\title{
Central Corneal Thickness in Adult Indians And its Effect on Glaucoma Progression: the Bundelkhand Region Glaucoma Study
}

\author{
Jitendra Kumar ${ }^{1}$,Amit Verma ${ }^{2}$, Shweta Dwivedi ${ }^{3}$, Arun Pathak ${ }^{4}$ \\ ${ }^{1}$ Associate Professor, Department Of Ophthalmology, Maharani Laxmi Bai Medical College, Jhansi, UP, India \\ ${ }^{2}, 3,4$ Junior Resident, Department Of Ophthalmology, Maharani Laxmi Bai Medical College, Jhansi, UP, India
}

\begin{abstract}
:
Introduction : Central corneal thickness plays an important role in understanding the risk of glaucoma. Corneal thickness of less than 555um provides false results of low intra ocular pressure, whereas, corneal thickness of more than 555 $\mathrm{m}$ provides a false result of raised intra ocular pressure when measured with tonometry. Intraocular pressure (IOP) is an important clinical outcome in glaucoma diagnosis.

Material and methods: Observational cross sectional study was conducted in between April 2016- April 2017. In this study 600 subjects were taken without any ocular pathological conditions aged 18 to 40 years were examined at a dedicated facility in the hospital. All subjects underwent a complete ophthalmic examination that included CCT measurements with an Spectral Domain Optical Coherence Tomography(SD-OCT) and intra ocular pressure (IOP) measurements with Schiotz tonometry.

Result: In males, the mean central corneal thickness (CCT) was $532.44 \pm 31.46$ in right eyes, and $533.05 \pm 31.03$ in left eyes. In females, the mean central corneal thickness was $525.63 \pm 31.73$ in right eyes and $526.26 \pm 33.86$ in left eyes. In men, the mean intraocular pressure in the right and left eyes respectively was 16.84 \pm 3.17 , 16.66 \pm 3.27 , in females it was $16.62 \pm 3.30,17.18 \pm 3.14$ in right and left eyes respectively.

Conclusion: In this population-based study, females had thinner central corneas as compare to males. These findings will have implications in the diagnosis and management of glaucoma in this population. Evaluation and changes of central corneal thickness is important clinical outcome to early diagnosis and management of glaucoma suspects .
\end{abstract}

Keywords:,central corneal thickness, glaucoma, Intraocular pressure, optical coherence tomography

\section{Introduction}

Optical coherence tomography (OCT) enables high-resolution imaging of the anterior segment of the human eye. In a noncontact examination it is possible to analyze layers and shape of cornea in cross-sectional images. This includes the option to determine central corneal thickness. Central corneal thickness itself affects the accuracy of intraocular pressure measurements ${ }^{[1] .}$ In the last decades, correlations between central corneal thickness and intraocular pressure readings have been evaluated in many studies establishing the correlation between these two ocular parameters ${ }^{[2-12] .}$. Many of these studies have used optical or ultrasonic pachymetry for corneal thickness measurements and applanation tonometry for intraocular pressure measurement. Nowadays, noncontact tonometry is widely used in clinical daily routine for screening purposes ${ }^{[13] .}$ Therefore, the relationship of this measurement technique with central corneal thickness readings as determined by spectraldomain OCT (SD-OCT) imaging should be further investigated. For clinical evaluation of central corneal thickness as determined by SD-OCT, it is essential to know physiological factors that are associated with the dimensions of the tissue.

Intraocular pressure readings are influenced by central corneal thickness (CCT) and may therefore affect diagnosis, screening, and the management of patients with glaucoma and ocular hypertension. There is evidence that IOP may be underestimated in patients with thinner and overestimated in patients with thicker corneas ${ }^{[14]}$ Central corneal thickness of ocular hypertensive patients is also presumed to be a powerful predictor of glaucoma development, as eyes with corneal thickness of 555 microns or less showed a greater risk of developing glaucoma than those with a corneal thickness of more than 588 microns ${ }^{[15] .}$ Many factors can affect CCT in the general population, such as age, gender, environmental and genetic factors, and race. The Ocular Hypertension Treatment Study demonstrated a correla-tion between greater mean central corneal thickness and younger age, female gender, and diabetes. Patients with ocular hypertension had thicker corneas than the general population ${ }^{[16] .}$ In contrast, other studies found a correlation between higher CCT and male gender and older age ${ }^{[17,18]}$. 


\section{Material And Methods}

A total 600 subjects were taken in this study from the outdoor patient department of the Department of Ophthalmology, Maharani Laxmi Bai Medical College, Jhansi, Uttar Pradesh, India over a period of 12 months from April 2016 to April 2017. The procedures followed were in accordance with the ethical standards committee on human experimentation (institutional or regional) and with the Helsinki Declaration of 1975, as evised in 2000. The necessary permission from the Ethical and Research Committee was obtained for the study. In this study 600 subjects were taken without any ocular pathological conditions aged from 18 to 40 years were examined in our department. All subjects underwent a complete ophthalmic examination that included CCT measurements with an SD-OCT and IOP measurements with Schiotz tonometry.

\section{Results}

Our study shows that the thicker central corneas of men as compare to females and the IOP is within normal range in both groups .In males, the mean central corneal thickness (CCT) was 532.44 \pm 31.46 in right eyes, and 533.05 \pm 31.03 in left eyes. In females, the mean central corneal thickness was $525.63 \pm 31.73$ in right eyes and 526.26 \pm 33.86 in left eyes (table.1). In men, the mean intraocular pressure in the right eyes $16.84 \pm 3.17$ and left eyes was 16.66 \pm 3.27 , in females it was $16.62 \pm 3.30$ in right eyes and 17.18 \pm 3.14 left eyes (table.2).

Table.1

\begin{tabular}{|l|l|l|}
\hline \multicolumn{3}{|c|}{ Central corneal thickness(Mean \pm SD) in micron } \\
\hline Sex & Right Eye & Left Eye \\
\hline Male & $532.44 \pm 31.46$ & $533.05 \pm 31.03$ \\
\hline Female & $525.63 \pm 31.73$ & $526.26 \pm 33.86$ \\
\hline
\end{tabular}

Table.2

\begin{tabular}{|l|l|l|}
\hline \multicolumn{3}{|c|}{ IOP(Mean \pm SD $)$ in $\mathbf{~ m m H g}$} \\
\hline Sex & Right Eye & Left Eye \\
\hline Male & $16.84 \pm 3.17$ & $16.66 \pm 3.27$ \\
\hline Female & $16.62 \pm 3.30$ & $17.18 \pm 3.14$ \\
\hline
\end{tabular}

\section{Statystical analysis}

For all quantitative variables Mean \pm SD were calculated. Through Pearson Correlation test, relation between central corneal thickness and intraocular pressure was calculated and statistical signifiance value at $\mathrm{P}<0.05$ in this study .

\section{Discussion}

The mean CCT was found to be $535.46+/-33.39$ in African American, $552.59+/-34.48$ in Caucasian ${ }^{[19]}$ In south Indian population CCT was $511.4+/-33.5$. In males, it was $515.6+/-33$, in females it was $508.0+/-32.8^{[20]}$. Our study population consists of patients who were age between 18 to 40 years. Factors which influence the intraocular pressure apart from central corneal thickness were not included in this study. Central corneal thickness of less than $555 \mu \mathrm{m}$ could be a reason for pseudo low intraocular pressure in our subjects.

\section{Conclusion}

Through our study we had concluded that there was an influence of central corneal thickness on intraocular pressure in adult Indians in bundelkhand region. There is a need for evaluation of central corneal thickness in patients who were presented with symptoms of glaucoma, but, with low intraocular pressure as it helps in providing effective intervention for controlling intraocular pressure and preventing optic nerve damage. CCT was positively correlated with IOP and men had thicker central corneas .

\section{References}

[1]. M. M. Whitacre, R. A. Stein, and K. Hassanein, "The effect of corneal thickness on applanation tonometry," American Journal of Ophthalmology, vol. 115, no. 5, pp. 592-596, 1993.

[2]. E. M. Hoffmann, J. Lamparter, A. Mirshahi et al., "Distribution of central corneal thickness and its association with ocular parameters in a large central european cohort: the gutenberg health study," PLoS ONE, vol. 8, no. 8, Article ID e66158, 2013.

[3]. M. Kohlhaas, A. G. Boehm, E. Spoerl, A. Pürsten, H. J. Grein, and L. E. Pillunat, "Effect of central corneal thickness, corneal curvature, and axial length on applanation tonometry," Archives of Ophthalmology, vol. 124, no. 4, pp. 471-476, 2006.

[4]. B. A. Francis, A. Hsieh, M.-Y. Lai et al., "Effects of corneal thickness, corneal curvature, and intraocular pressure level on goldmann applanation tonometry and dynamic contour tonometry," Ophthalmology, vol. 114, no. 1, pp. 20-26, 2007.

[5]. P.-A. Tonnu, T. Ho, T. Newson et al., "The influence of central corneal thickness and age on intraocular pressure measured by pneumotonometry, non-contact tonometry, the Tono-Pen XL, and Goldmann applanation tonometry," British Journal of Ophthalmology, vol. 89, no. 7, pp. 851-854, 2005.

[6]. T. T. Wong, T. Y. Wong, P. J. Foster, J. G. Crowston, C.-W. Fong, and T. Aung, "The relationship of intraocular pressure with age, systolic blood pressure, and central corneal thickness in an Asian population," Investigative Ophthalmology \& Visual Science, vol. 50, no. 9, pp. 4097-4102, 2009. 
[7]. H. Zhang, L. Xu, C. Chen, and J. B. Jonas, "Central corneal thickness in adult Chinese. Association with ocular and general parameters. The Beijing eye study," Graefe's Archive for Clinical and Experimental Ophthalmology, vol. 246, no. 4, pp. 587-592, 2008.

[8]. V. Nangia, J. B. Jonas, A. Sinha, A. Matin, and M. Kulkarni, "Central corneal thickness and its association with ocular and general parameters in Indians: the Central India Eye and Medical Study,” Ophthalmology, vol. 117, no. 4, pp. 705-710, 2010.

[9]. R. C. W. Wolfs, C. C. W. Klaver, J. R. Vingerling, D. E. Grobbee, A. Hofman, and P. T. V. M. De Jong, "Distribution of central corneal thickness and its association with intraocular pressure: the Rotterdam study," American Journal of Ophthalmology, vol. 123, no. 6, pp. 767-772, 1997.

[10]. T. Eysteinsson, F. Jonasson, H. Sasaki et al., "Central corneal thickness, radius of the corneal curvature and intraocular pressure in normal subjects using non-contact techniques: Reykjavik Eye Study,” Acta Ophthalmologica Scandinavica, vol. 80, no. 1, pp. 11$15,2002$.

[11]. A. Tomidokoro, M. Araie, and A. Iwase, "Corneal thickness and relating factors in a population-based study in Japan: the Tajimi study," American Journal of Ophthalmology, vol. 144, no. 1, pp. 152-154, 2007.

[12]. M. J. Doughty and M. L. Zaman, "Human corneal thickness and its impact on intraocular pressure measures: a review and metaanalysis approach," Survey of Ophthalmology, vol. 44, no. 5, pp. 367-408, 2000.

[13]. J. Myint, D. F. Edgar, A. Kotecha, I. E. Murdoch, and J. G. Lawrenson, "A national survey of diagnostic tests reported by UK community optometrists for the detection of chronic open angle glaucoma," Ophthalmic and Physiological Optics, vol. 31, no. 4, pp. 353-359, 2011.

[14]. Whitacre MM, Stein RA, Hassanein K (1993) The effect of corneal thickness on applanation tonometry. Am J Ophthalmol 115: 592-596

[15]. Gordon MO, Beiser JA, Brandt JD, Heuer DK, Higginbotham EJ, et al. (2002) The Ocular Hypertension Treatment Study: baseline factors that predict the onset of primary open-angle glaucoma. Arch Ophthalmol 120: 714-720; discussion 829-730.

[16]. Brandt JD, Beiser JA, Kass MA, Gordon MO (2001) Central corneal thickness in

[17]. the Ocular Hypertension Treatment Study (OHTS). Ophthalmology 108: 1779-1788.

[18]. Vijaya L, George R, Arvind H, Ve Ramesh S, Baskaran M, et al. (2010) Central

[19]. corneal thickness in adult South Indians: the Chennai Glaucoma Study. Ophthalmology 117: $700-704$.

[20]. Tomidokoro A, Araie M, Iwase A (2007) Corneal thickness and relating factors

[21]. in a population-based study in Japan: the Tajimi study. Am J Ophthalmol 144:152-154.

[22]. Shen SLam D. Intraocular pressure, goldmann applanation tension, corneal thickness, and corneal curvature in Caucasians, Asians, Hispanics, and African Americans. American Journal of Ophthalmology. 2004;137:597-598.

[23]. Vijaya L, George R, Arvind H, Ve Ramesh S, Baskaran M, Raju P et al. Central Corneal Thickness in Adult South Indians. Ophthalmology. 2010;117:700-704 